\title{
Erratum to: Quantifying a Sustainable Management Space for Human Use of Coastal Groundwater under Multiple Change Pressures
}

\author{
K. Mazi ${ }^{1,2,3}$ A. D. Koussis ${ }^{2,3}$ - G. Destouni ${ }^{1,3}$
}

Published online: 18 July 2016

(C) Springer Science+Business Media Dordrecht 2016

\section{Erratum to: Water Resour Manage}

\section{DOI 10.1007/s11269-016-1363-1}

Due to an oversight, Eqs. (2a) and (2b) were incorrectly captured in the original publication. The correct presentation for both equations are shown below.

$$
\begin{gathered}
\frac{\ell_{\mathrm{T}}}{L}=\frac{\ell_{\mathrm{w}}}{L} \quad \text { for } 0 \leq q_{\mathrm{r}} \leq q_{\mathrm{r}}^{\max } \\
\frac{\boldsymbol{\ell}_{\mathrm{T}}}{L}=\frac{\boldsymbol{\ell}_{\mathrm{div}}}{L}=\frac{1}{r L} q_{\mathrm{r}}+\frac{\boldsymbol{\ell}_{\mathrm{w}}}{L} \quad \text { for } q_{\mathrm{r}}^{\min }<q_{\mathrm{r}} \leq 0
\end{gathered}
$$

The online version of the original article can be found at http://dx.doi.org/10.1007/s11269-016-1363-1

\section{K. Mazi}

kmazi@noa.gr

1 Department of Physical Geography, Bolin Centre for Climate Research, Stockholm University, SE-106 91 Stockholm, Sweden

2 Institute for Environmental Research and Sustainable Development, National Observatory of Athens, I. Metaxa \& Vas. Pavlou Str, GR-152 36 Athens, Palea Penteli, Greece

3 Navarino Environmental Observatory (NEO), Messinia, GR-240 01 Kalamata, Greece 